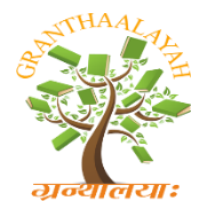

Science

\title{
A CRITICAL ANALYSIS OF THE RELATIONSHIP BETWEEN ANTHROPOMETRIC INDICATORS OF OBESITY AMONG THE POST GRADUATE GIRLS (18-22 YEARS)
}

\author{
Vandana Mishra ${ }^{* 1}$ \\ ${ }^{*}$ Assistant Professor, Department of Home Science, Pushp Institute of Science and Higher \\ Studies, Pilibhit (UP), India
}

\begin{abstract}
Asians Indian are commonly dyslipidemia and predisposed to develop accelerated arthrosclerosis. The present study was done to critical analyze of the different anthropometric indicators of obesity such as body mass index, waist - hip ratio and waist circumference.

The sample comprised of 150 females (mean age $=20.6$ years) selected randomly from post graduate student of Banasthali University. A questionnaire was framed to collect the information from the respondent such regarding personal profile, physical activity and dietary pattern, different anthropometric measurements (height, weight, waist and hip circumference), BMI and WHR were calculated using standard techniques.

The results of the study revealed that mean value of BMI and WHR of all respondents were 20.80 and 0.78 respectively. The result showed that according to BMI 49.3 per cent of respondents were normal while 1.3 per cent of respondents were in obese category.

According to WHR prevalence of obesity was seen in 14.76 per cent of respondents. They all had risk of obesity associated diseases and other metabolic disorder while 83.39 per cent of the respondents had normal waist circumference they had no risk of metabolic complication. Thus, the study shows WHR is more useful and simple anthropometric indicator of obesity.
\end{abstract}

Keywords: Anthropometry; Obesity; Body Mass Index and Waist Hip Ratio.

Cite This Article: Vandana Mishra. (2018). "A CRITICAL ANALYSIS OF THE RELATIONSHIP BETWEEN ANTHROPOMETRIC INDICATORS OF OBESITY AMONG THE POST GRADUATE GIRLS (18-22 YEARS)." International Journal of Research Granthaalayah, 6(6), 45-48. https://doi.org/10.29121/granthaalayah.v6.i6.2018.1333.

\section{Introduction}

The anthopometry has a Greek origin meaning human (anthropes) measurement (metery). The techniques involve the measurement of whole body (body weight) and part there of physique e.g. height, thickness of skinfolds arms muscles, head and chest circumference. (Sharma, 2008). 
Anthropometry is one of the most basic classification for assessing nutritional status, whether over nutrition or under nutrition. A variety of methods are available to measure obesity and body thinness. However, waist circumference and waist hip ratio are useful in predicting health outcomes and innovative measurement of body fat or obesity. Previously WHR was used for assessment for abdominal fat but now a day it is shifted to WC. Waist circumference has been shown the best simple measure of both intra-abdominal fat mass and tatal fat. Currently, there are many measures for diagnosing obesity at population level but most frequently used diagnostic tool in current classification system of obesity is body mass index (Soni A,Verma V,2013).

Overweight specifically refers to an excess body weight compared to set standards (Zafar $\boldsymbol{e t} \boldsymbol{a l}$, 2007). There are many sites of fat distribution in body like skin, visceral identified of two types Android and Gynoid. Android type of obesity is likened to the shape of apple. The shoulders, face, arms, neck, chest and upper portion of abdomen are bloated. Gynoid is type the lower part of the body has the extra flesh. This type of obesity is similar to pears (Ketel et al, 2007).

Overweight and obesity has emerged a major disorder associated with many metabolic diseases in both developed and developing countries. Globally it is predicted that by 2020 non communicable diseases will contribute to $80 \%$ of the global burden of diseases causing 7 out of 10 deaths in developing countries (Vijaylakshmi K and Aruna M, 2014).

\section{Methodology}

The present study was carried out in Banasthali University, Rajasthan. The study was taken to assess the anthropometrical indicators (height, weight and waist hip ratio) among 150 post graduate students (girls) between the age of $18-22$ years selected randomly. All girls were belonged to different state and were vegetarians. Personal information about age, dietary pattern and demographic profile were collected through questionnaire. Each student was contacted personally at their hostel. The body height measured with an anthrometer in standing erect position, to the nearest $0.9 \mathrm{~cm}$. Body weight was measured on electronic digital scale with in aquracy of up to $0.1 \mathrm{~kg}$. Waist and hip circumference was measured. Percent mean and standard deviation was calculated. In general BMI = weight $(\mathrm{kg}) /$ height $(\mathrm{m} 2)$ and WHR = waist $/$ hip for assessment of overweight and obesity.

\section{Result}

\subsection{Selection of the Respondents}

As selected respondents belonged to post graduate courses. Their mean age was 19.7 years. All were females. They belong to middle income group and upper income group and follow on sedentary pattern of life. All the respondents $(n=150)$ were vegetarian because they had to strictly follows vegetarism in Banasthali University. They took four meal pattern diet which provide around $1996.7 \mathrm{kcal}$ and $76.38 \mathrm{~g}$ protein daily. Student belonged to different states and they live in hostel. 
Table no 1 indicated that majority of the respondent i.e. 40 per cent were belonged to the UP state while 22 percent of the respondent were belonged to the Rajasthan. Only 10 per cent of the respondents were belonged to the Bihar.

Table 1: Distribution of respondent according to their belongingness $(n=150)$

\begin{tabular}{|l|l|l|}
\hline State & Number of student & Percent \\
\hline Punjab & 21 & 14 \\
\hline Bihar & 15 & 10 \\
\hline UP & 60 & 40 \\
\hline MP & 4 & 2.6 \\
\hline Rajasthan & 33 & 22 \\
\hline Uttarakhand & 17 & 11.3 \\
\hline
\end{tabular}

\subsection{Anthropomertric evaluation}

Body mass index (BMI) is a scale used for determining the weight status of an individual in relation to height and associated risk. BMI has different categories which show the nutritional status of a person. So, BMI of respondents has been shown in Table no. 2.

Data in Table no. 2 revealed that 49.3 per cent of the respondents $(n=74)$ were having normal $\mathrm{BMI}$ range $20-25$ and their mean value of BMI as $22.16 \pm 1.62$. The results showed that they have normal weight status.

Respondents who had slightly lower weight were 18.8 per cent $(n=28)$ with BMI range $18.5-20$ and their mean value of BMI was $19.30 \pm 0.34$. According to the study again $18.6 \%$ per cent of the respondents $(n=28)$ with BMI range $17-18.5$ and their mean was $17.86 \pm 0.48$. They also had slightly low weight and prone to mal nutrition while 7.3 percent of respondents $(n=18)$ lie below 17 BMI range. They had their mean BMI was $16.22 \pm 0.59$. They come in malnutrition category.

The study showed that only 4.6 per cent of the respondents $(n=7)$ comes in slightly overweight category ( $25-30$ BMI range). Their mean value was $28.73 \pm 1.25$ i.e. they were prone to obesity also have different associated diseases. Another 1.3 per cent of subjects $(n=2)$ had high BMI range $30-40$ i.e. obese grade 2 . They had high body fat. These respondents were prone to different associated diseases like cardiovascular and diabetes etc.

Table 2: Evaluation of BODY MASS INDEX (BMI) $(n=150)$

\begin{tabular}{|c|c|c|c|}
\hline BMI range & No. of respondents & Percent & Mean $\pm \mathrm{SD}(\mathrm{BMI})$ \\
\hline Above 40 (obese grade 3$)$ & 0 & 0 & 0 \\
\hline $30-40$ (obese grade 2$)$ & 2 & 1.3 & $32.40 \pm 0.14$ \\
\hline $25-30$ (obese grade 1$)$ & 7 & 4.6 & $28.13 \pm 1.25$ \\
\hline $20-25$ (normal) & 74 & 49.3 & $22.16 \pm 1.62$ \\
\hline 18.5- 20 (low weight- normal) & 28 & 18.6 & $19.30 \pm 0.34$ \\
\hline $\begin{array}{l}\text { 17- } 18.5 \text { (chronic energy deficiency grade } 1 \text { - } \\
\text { mild) }\end{array}$ & 28 & 18.6 & $17.86 \pm 0.48$ \\
\hline Below 17 (chronic energy grade 2- moderate) & 11 & 7.3 & $16.22 \pm 0.57$ \\
\hline Total & 150 & - & 20.80 \\
\hline
\end{tabular}




\subsection{Waist - Hip Circumference}

Waist - hip circumference of all respondents were measured by dividing waist circumference with hip circumference. This has been found to be a better marker of abdominal obesity was calculated and defind as the basis of WHR (Zafar, 2007). The cut off value of central obesity was considered $\geq 0.95$ in males while normal value for females was $\geq 0.80$ (WHO, 1998). The WHR has been used in a number of epidemiologic studies to show increased risk for diabetes, coronary artery diseases and hypertension (Albu et al, 1997).

The data in Table no. 3 stated that 83.3 percent of respondents $(n=125)$ had normal WHR category and their mean value of WHR was $0.77 \pm 0.038$. This showed their low risk for cardiovascular diseases and diabetes. Another 14.70 per cent of respondents $(n=21)$ had high WHR range (Above -0.85 ). They are prone different obesity associated diseases. Their mean was $0.88 \pm 0.02$ (Table no. 3). Only 2.66 percent of the respondents $(n=4)$ had slightly lower WHR (below -0.7$)$. They had low abdominal obesity. It showed they were less prone or risk for other obesity associated diseases.

Table 3: Waist hip circumference ratio of subjects of respondents $(n=150)$

\begin{tabular}{|l|l|l|l|}
\hline Waist hip ratio & No. of subjects & Percent & Mean \pm SD(WHR) \\
\hline Below 0.7 & 4 & $2.66 \%$ & $0.61 \pm 0.066$ \\
\hline $0.7-0.85$ & 125 & $83.39 \%$ & $0.77 \pm 0.038$ \\
\hline Above 0.85 (central obesity) & 21 & $14.76 \%$ & $0.88 \pm 0.028$ \\
\hline Total & 150 & - & 0.78 \\
\hline
\end{tabular}

\section{Conclusion}

According to BMI only 5.9 per cent of respondents had high BMI range ( $\geq 25)$. Only 49.3 per cent respondents were in normal BMI and 44.5 per cent subjects were in low BMI range $(\leq 18.5)$. According to WHR classification 83.3 per cent of respondents had normal WHR range $0.7-0.85$. Only 2.66 per cent of respondents had below than 0.7 WHR and 14.76 respondents had WHR above 0.85 . This showed that more than half subjects were not identified obese through WHR. Waist circumference was independently analysed and it was found that $80 \%$ of subjects had normal waist circumference.

\section{References}

[1] Ketel JG, Volman MNM, Seidell JC, Stechouwer DA, Twist Jos W and Lambalk CB. Obesity and type of obesity. 2007; 156:655-661.

[2] Sharmas Body composition, nutritional anthropometry.2008, 1st ed; 256-261.

[3] Soni A, Verma V.Anthropometric indicators of obesity and percent body fat - A measure for weight management. Internatinal journal of science and research, 2013; 2229.

[4] Vijayalakshmi K and Aruna M. International journal of food and nutritional sciences.2014; 153.

[5] Zafar S, Haque Iu, Butt AR, Mirza HG, Shafiq F, Rehman AV. Pakistan journal of medical science, Health hazards of obesity.2007;23:574-579.

*Corresponding author.

E-mail address: vandanabhi.life1987@ gmail.com 